\title{
An Efficient Digital Space Vector PWM Module for 3- $\Phi$ Voltage Source Inverter (VSI) on FPGA
}

\author{
Shalini Vashishtha ${ }^{1}$ \\ Research Scholar \\ Dept. of ECE, SJBIT Research Center \\ Bangalore, India
}

\author{
Rekha K.R ${ }^{2}$ \\ Professor \\ Dept. of ECE, SJBIT \\ Bangalore, India
}

\begin{abstract}
The realization of digital control circuitry based PWM strategies provides many advantages. It includes better prototyping, higher switching frequency, simple hardware, and flexibility by overcoming the limitations of analog control strategies. In this article, The Digital space vector-based Pulse width Modulation ((DSV-PWM) is designed. The DSV-PWM Module includes, mainly, Xdq reference frame, Sector generation, Square root, switching time generation, Carry-save adder (CSA), and PWM Generation module. These modules are designed using simple logical operations, and combinational circuits to improve the DSV-PWM performance. The DSV-PWM Module is synthesized and implemented on a cost-effective Artix7 FPGA device. The present work utilizes a $<1 \%$ chip area, operates at $597.83 \mathrm{MHz}$ of maximum frequency, and utilizes $110 \mathrm{~mW}$ of total power on FPGA Device. The DSV-PWM module is also compared with the existing SV-PWM approach with better improvement in hardware constraints like chip area, operating frequency, and dynamic power $(\mathrm{mW})$.
\end{abstract}

Keywords-Digital space vector PWM; 3-phase voltage source inverter; sector generation module; switching time generation; FPGA; Verilog-HDL; Xilinx

\section{INTRODUCTION}

The development of AC motor drives with present technology becomes major highlight for delivering a suitable amount of energy to the motor. This is achieved with the drastic improvements and advancement in the microprocessor, power electronics technologies and switching power converters. The amount of energy is computed by Pulse width Modulated (PWM) signals. Most of the existing analog control circuitry provides excellent dynamic response, but failed to maintain circuit complexity, circuit modification, and has few functions. The present AC motor drives adopt the processor-based or advance technology like DSP, ASIC, or FPGA based digital control strategy. The digital control strategy overcomes the existing analog control strategy limitations with more significant improvement in circuit development. The commonly used PWM approaches include the Space Vector (SV)-PWM method, Sinusoidal-PWM method, and Hysteresis-PWM method [1-2].

The 3Ф--Voltage Source Inverter (VSI) provides the Variable supply voltage to AC motor drives and is used majorly in modern industrial applications. The PWM methods are used to modulate the VSI output voltage using different controlling strategies. The SV-PWM based VSI uses many topologies, which includes, High Power 2-level VSI and
Multi-level Inverter. The Multi-level inverter further classified has advanced bus Clamped-VSI, flying capacitor, or Diode Clamped-VSI and Neutral point Clamped VSI [3].

The FPGA and DSP based Controlling strategies assist different digital AC-Motor drives to control the motor. The DSP based approaches provide great features like simple circuitry, flexibility to use for many applications and softwarebased control strategies. But failed to maintain the bandwidth performance because of the high sampling rate used in the current control loop and PWM generation. The current control loop and PWM generation use most of the computational resources in the controller and only limited time is available to control other specified functions in the Drive. To fulfill the limitations of DSP based Controlling strategies, The FPGA /ASIC based PWM controlling strategies are used for AC motor drives. There is rapid development in FPGA, which offers faster circuit response continuously and supports parallel processing rather than sequential execution and more excellent speed control capability of $3 \Phi$-induction motors [4-5]. The FPGA is a reprogrammable device that contains logical interconnection and logical Blocks. The logical blocks are designed with the help of logical operations, combinational, and sequential circuits. The FPGA is user friendly, avoids the high NRE cost, inflexibilities, and development cycles than the conventional ASIC approach [6-9].

In this article, an efficient Digital space vector (DSV) Pulse width Modulation (PWM) is designed and implemented on low-cost Artix-7 FPGA. It provides high performance and less resource utilization on hardware and is suitable for realtime power electronics applications. The proposed design uses simple logical operations and combinational circuits to design the DSV-PWM, which assures low power consumption, less execution time, and high reduction in chip area in FPGA and also reduces the complexity in $3 \Phi$-VSI.

Section II describes the existing approaches of different SV-PWM techniques from different application viewpoints and also analyzes limitations. The proposed DSV-PWM module is described in detail with the basic principle and hardware architecture in section III. Section IV discusses the simulation results and performance analysis of the DSV-PWM method and also compares with the existing SV-PWM technique with constraints improvements. Finally, the section $\mathrm{V}$ concludes the Overall work with improvements and suggest the future scope. 


\section{RELATED WORKS}

This section discusses the existing approaches of different space vector (SV)-PWM techniques for different application usage. Janik et al. [10] present the SV-PWM technique without the usage of trigonometric operation to improve the hardware performance in real-time scenarios. The module investigates the multilevel converter (MLC) using independent voltage modulation. The MLC Module supports both DSP and FPGA operations on a single MLC interface unit with other supporting peripheral devices. Holtz et al. [11] present the SVModulator for Higher switching frequency control operation with the help of three-level Silicon-Carbide (SiC) Inverter. The design uses a two-level SV approach for switching time generation, and the Modulation module is designed based on logic decisions. The 3-Level Inverter is designed based on Circuit topologies, High-frequency PWM, Neutral point Potential (NPP) control, and 3-level Modulator. Kassas et al. [12] discuss the Look-Up Table (LUT) based SV-PWM, which is designed and implemented using simple 8-bit Microcontroller and also modeled using Simulink. The LUT used to improve the time assignment computation in 3- $\Phi$ VSI. The LUT based SV-PWM has three main modules includes PWM Timer, High, and low-priority interrupt modules for total harmonic distortion (THD) and error Calculation.

Celik et al. [13] present the real-time SV-PWM signal generation using FPGA Device. The PWM signals used to control the VSI are achieved on FPGA prototype circuit. The SV-PWM design results are verified using a time-domain simulation using Matlab Simulink. Liang et al. [14] present the SV-PWM based control algorithm on FPGA and also verify the FPGA design with a Software-based SV-PWM approach using Matlab Simulink. The SV-PWM Control algorithm includes the sector determination for any space vector, time-domain voltage space vector function generation, switching time, and conduction module. Lotfi et al. [15] discuss the SV-PWM module for voltage inverter-based AC machines. The module includes Voltage reference calculation, Sector determination, Switching time calculation, and also a series of PWM Pulses. The design uses more LUTs, consumes more chip areas and not significant for real-time applications.

The SV-PWM computations are designed for multi-level inverter by Salem et al. [16] and also for open end-winding induction machine (OEWIM) using Dual 3-level T-type converter. The operation of a 3-level dual T-Type converter is designed using vector diagrams and switching states, Sector and region identification, time interval calculation, and switching pattern modules. The design also analyzes the Voltage and current THD against different switching frequencies. $\mathrm{Pu}$ et al. [17] describe the Random SV-PWM technique for $3 \Phi$ - VSI on FPGA, which includes a randomization algorithm for faster and flexible realization hardware. The Random -SV-PWM has a waveform generation module, Pseudo random signal generation module, and PWM generation module. The random SV-PWM results are useful in terms of standard Line Voltage, wave filtering of Line Voltage, FFT of Line Voltage than conventional PWM approaches. Khlavi et al. [18] present the reconfigurable PWM Generator on FPGA for power electronics appliances. The module is implemented on both ASIC and FPGA, which can be configured easily with different PWM strategies. Garcia et al. [19] discuss the SV-PWM control module for 2 levels 3Фinverter on Matlab GUI and FPGA. The design also supports a simplified education platform for teaching SV-based PWM techniques. Suma et al. [20-21] present the FPGA controller for an Induction Motor drive and also SV-PWM based design for 3-level Inverter on non-volatile FPGA. Chinmaya et al. [22] present the analyses of different SV-PWM methods like Conventional SV-PWM, Vector space decomposition-based, vector classification based, and Common mode voltage injection-based SV-PWM approaches for dual $3 \Phi$ induction motor drive.

The proposed work overcomes the conventional SV-PWM methods by considering the performance and accuracy of the FPGA system. The present work reduces overall system cost and chip area for $3 \Phi$-VSI on FPGA, and also present work ensures the great flexibility in FPGA for usage in real-time Power electronics applications.

\section{PROPOSED WORK}

In this section, the Digital space vector-based Pulse width Modulation (DSV-PWM) designed for $3 \Phi$-Voltage source Inverter (VSI) is explained with basic principle and its hardware architectures.

\section{A. Basic Principle of SV-PWM}

The Digital SV-PWM provides the low-current -ripple and DC-Link Voltage with better resource utilization, Lower harmonic content, Wider linear modulation index range than the conventional-SV-PWM approaches. The SV-PWM is implemented using Voltage equations in the form of the abc reference frame. This frame is converted to the $d-q$ reference frame, and it has a horizontal (d) and vertical (q) axis. It can be determined by the Reference voltage space vector $\left(\mathrm{V}_{\mathrm{ref}}\right)$, which is rotating in a circular position that constitutes a sinusoidal waveform, and it is represented in Fig. 1.

The Reference Voltage space vector estimates the combination of 8- switching forms $\left(\mathrm{V}_{0}\right.$ to $\left.\mathrm{V}_{7}\right)$ in the PWM Technique. The $\mathrm{V}_{1}$ to $\mathrm{V}_{6}$ active (Switching) vectors are divided into 6 sectors in a hexagonal plane, and each of the sectors is arranged in 60 degrees. The $V_{0}$ and $V_{7}$ are null vectors. The $\mathrm{V}_{\text {ref }}$ is calculated using two null vectors and any two actives (Switching) vectors, and it is represented in Fig. 2.

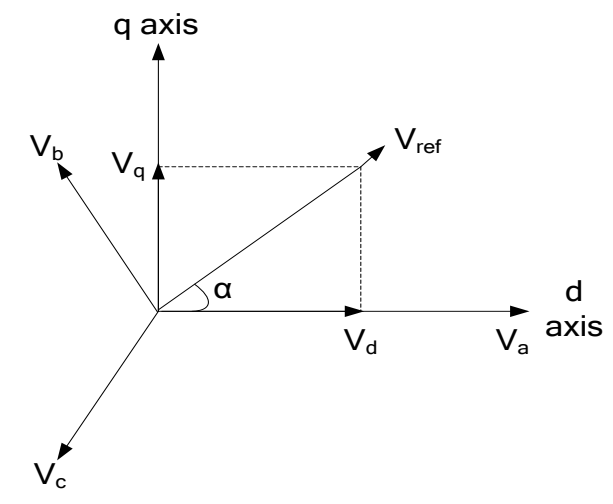

Fig. 1. Reference Voltage Space Vector. 


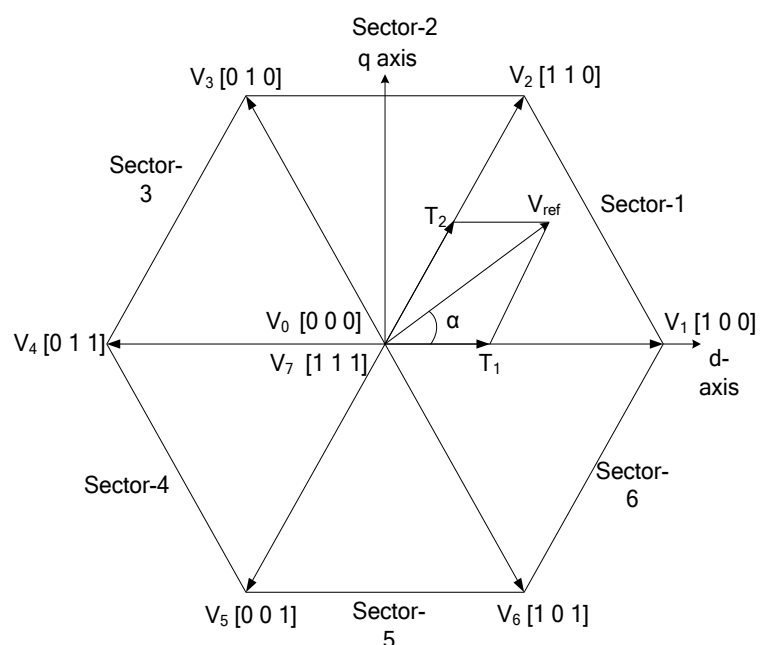

Fig. 2. Fundamental Sectors and Switching Vectors.

The three-phase voltage vector $\left[\mathrm{V}_{\mathrm{a}}, \mathrm{V}_{\mathrm{b}}, \mathrm{V}_{\mathrm{c}}\right]$ and switching variable vector relationships are described as follows [9]:

$$
\left[\begin{array}{l}
V_{d} \\
V_{q}
\end{array}\right]=\frac{2}{3}\left[\begin{array}{ccc}
1 & -1 / 2 & -1 / 2 \\
0 & \sqrt{3} / 2 & -\sqrt{3} / 2
\end{array}\right]\left[\begin{array}{l}
V_{a} \\
V_{b} \\
V_{c}
\end{array}\right]
$$

The reference voltage and angle are derived using eq (2) and eq (3) as follows:

$$
\begin{aligned}
& \left|V_{r e f}\right|=\sqrt{V_{d}^{2}+V_{q}^{2}} \\
& \alpha=\tan ^{-1}\left(\frac{V_{q}}{V_{d}}\right)=\omega_{s} t=2 \pi f_{s} t
\end{aligned}
$$

Where $\mathrm{f}_{\mathrm{s}}$ is the fundamental frequency.

\section{B. Proposed Hardware Architecture of DSV-PWM}

The Hardware architecture of the DSV-PWM method is represented in Fig. 3. The DSV-PWM mainly consists of Xdq Module, Sector generation module (SGM), Switching Time Module (STM), Square root module, Carry save Adder (CSA) module, and PWM generation module. These modules are constructed using simple Logical and combinational circuits, which provide higher performance keeping the hardware constraints into consideration.

The Xdq Module is designed using equation (1), and it is simplified using intermediate vectors $X_{d}$ and $X_{q}$ by equation (4) and equation (5) respectively, as follows:

$$
\begin{aligned}
& X_{d}=2 V_{a}-V_{b}-V_{c} \\
& X_{q}=V_{b}-V_{c}
\end{aligned}
$$

The $\mathrm{X}_{\mathrm{dq}}$ Module simulation results are represented in Fig. 4. The $\mathrm{X}_{\mathrm{dq}}$ Module uses simple multiplier and subtractors

\begin{tabular}{|c|c|c|c|c|c|c|c|}
\hline /va & -56 & 10 & 17 & 2 & & 111 & -56 \\
\hline$/ v b$ & -44 & 0 & 16 & 4 & & -44 & \\
\hline /vc & -1 & 0 & 30 & 1 & -56 & -1 & \\
\hline /xq & -43 & 0 & -14 & 3 & 60 & -43 & \\
\hline /xd & -67 & 0 & -12 & -1 & 56 & 11 & -67 \\
\hline
\end{tabular}
to generate the 8-bit $X_{d}$ and $X_{q}$ outputs by using the 8-bit $V_{a}$, $\mathrm{V}_{\mathrm{b}}$, and $\mathrm{V}_{\mathrm{c}}$ inputs.

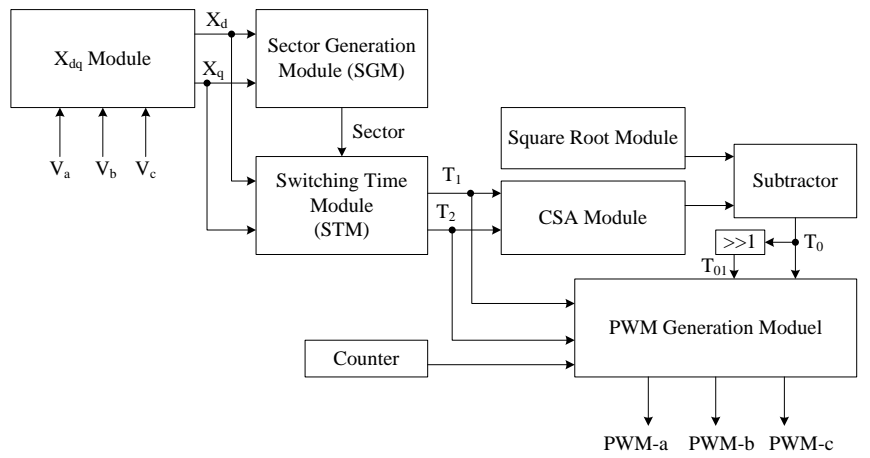

Fig. 3. Proposed Hardware Architecture of DSV-PWM Module.

Fig. 4. Simulation Results of $\mathrm{X}_{\mathrm{dq}}$ Module.

The switching variable vectors $\mathrm{V}_{\mathrm{d}}$ and $\mathrm{V}_{\mathrm{q}}$ are expressed by using the $X_{d}$ and $X_{q}$ in equation (6) as follows:

$V_{d}=\frac{1}{3}\left[X_{d}\right]$ And $V_{q}=\frac{1}{\sqrt{3}}\left[X_{q}\right]$

The sector generation module (SGM) is designed by using three conditions (a) sign of $X_{d}$, (b) Sign of $X_{q}$, and (c) $\left|X_{d}\right|=\left|X_{q} / 2\right|$. The design uses simple combinational circuits to design these conditions. The one-bit right shift operation achieves the $\mathrm{X}_{\mathrm{q}} / 2$. The sector generation is based on the following 6 rules, and it is tabulated in Table I.

The simulation results of SGM is represented in Fig. 5 using 8-bit $X_{d}$ and $X_{q}$ inputs along with 3-bit select line. The SGM generates the 3bit sector outputs. The SGM Hardware architecture, uses two signed Shifter modules, three multiplexers, comparators, encoder and Bit-wise logical operations (NOT and AND-gates). These modules are combinational circuits and simple to design which consume little amount of power.

TABLE I. SECTOR GENERATION

\begin{tabular}{|l|l|l|l|}
\hline Rules & Condition & Sector \\
\hline Rule-1 & If $\left(\left(\mathrm{X}_{\mathrm{d}}>0\right) \&\left(\mathrm{X}_{\mathrm{q}}>0\right) \&\left(\mathrm{X}_{\mathrm{d}}>\mathrm{X}_{\mathrm{q}} / 2\right)\right)$ & 1 \\
\hline Rule-2 & If $\left(\left(\mathrm{X}_{\mathrm{d}}>0\right) \&\left(\mathrm{X}_{\mathrm{q}}>0\right) \&\left(\mathrm{X}_{\mathrm{d}}<\mathrm{X}_{\mathrm{q}} / 2\right)\right)$ & 2 \\
\hline Rule-3 & If $\left(\left(\mathrm{X}_{\mathrm{d}}<0\right) \&\left(\mathrm{X}_{\mathrm{q}}>0\right) \&\left(\mathrm{X}_{\mathrm{d}}>\mathrm{X}_{\mathrm{q}} / 2\right)\right)$ & 3 \\
\hline Rule-4 & If $\left(\left(\mathrm{X}_{\mathrm{d}}<0\right) \&\left(\mathrm{X}_{\mathrm{q}}<0\right) \&\left(\mathrm{X}_{\mathrm{d}}>\mathrm{X}_{\mathrm{q}} / 2\right)\right)$ & 4 \\
\hline Rule-5 & If $\left(\left(\mathrm{X}_{\mathrm{d}}>0\right) \&\left(\mathrm{X}_{\mathrm{q}}<0\right) \&\left(\mathrm{X}_{\mathrm{d}}<\mathrm{X}_{\mathrm{q}} / 2\right)\right)$ & 5 \\
\hline Rule-6 & If $\left(\left(\mathrm{X}_{\mathrm{d}}>0\right) \&\left(\mathrm{X}_{\mathrm{q}}<0\right) \&\left(\mathrm{X}_{\mathrm{d}}>\mathrm{X}_{\mathrm{q}} / 2\right)\right)$ & 6 \\
\hline
\end{tabular}

Fig. 5. Simulation Results of Sector Generation Module. 
The switching time module is designed based on Table II for the generation of $T_{1}, T_{2}$ and $T_{0}$ using 3-bit sector generation module inputs. The $T_{1}$ and $T_{2}$ are modeled using simple right shifter, addition, and subtraction operations by using $\mathrm{Xd}$ and $\mathrm{X}_{\mathrm{q}}$.

The $\sqrt{3}$ square root module is designed using a comparator, simple multiplier, and subtractor operations. The simulation results of square root module are represented in Fig. 6.

The Switching time $T_{0}$ is generated by subtracting $\sqrt{3}$ from $\left(T_{1}+T_{2}\right)$. The $\left(T_{1}+T_{2}\right)$ operation is designed using an 8bit carry-save adder (CSA). The CSA contains seven 2-bit Ripple carry adders (RCA) and three 6:3 Multiplexers. The carry-in is assumed as zero. The simulation results of 8-bit CSA are represented in Fig. 7.

The PWM module generation is designed by using the counter, Switching time and Sectors. The PWM module generation for sector -1 is tabulated in Table III. The Counter range is fixed to $2 \mathrm{~T}_{0}+2 \mathrm{~T}_{1}+2 \mathrm{~T}_{2}$. The PWM pulse of a, b, and $c$ is in the form of ' 0 ' or ' 1 '. The $T_{01}$ is used in Table III, which is generated using a one-bit right shifting of $\mathrm{T}_{0}$, and it is represented in Fig. 3. Similarly, by using Sector 2-6, with different switching times, the PWM pulses are generated for a, $\mathrm{b}$ and $\mathrm{c}$. The PWM module generation architecture uses simple shifters, adders, and multipliers. Overall, the present work uses only combinational circuits and Logical operations to construct the DSV-PWM module.

\begin{tabular}{l|l|l|l|l|l|l|l|l|l|l} 
data_in & 225 & 0 & 3 & 4 & 9 & 16 & 25 & 100 & 144 & 225 \\
\hline data_out & 15 & 0 & 1 & 2 & 3 & 4 & 5 & 10 & 12 & 15 \\
\hline & 0 &
\end{tabular}

Fig. 6. Simulation Results of Square Root Module.

\begin{tabular}{|c|c|c|c|c|c|c|}
\hline la & 43 & 14 & 3 & 26 & 139 & 43 \\
\hline$/ b$ & 39 & 109 & 0 & 60 & 161 & 39 \\
\hline / cin & 0 & & & & & \\
\hline /s & 82 & 123 & 3 & 86 & 44 & 82 \\
\hline /cout & 0 & & & & & \\
\hline
\end{tabular}

Fig. 7. Carry Save Adder (CSA) Module Simulation Results.

TABLE II. SWITCHING TIME GENERATION

\begin{tabular}{|l|l|l|l|}
\hline Sector & $\mathbf{T}_{1}$ & $\mathbf{T}_{2}$ & $\mathbf{T}_{\mathbf{0}}$ \\
\hline 1 & $\mathrm{X}_{\mathrm{d}}-\left(\mathrm{X}_{\mathrm{q}}>>1\right)$ & $\mathrm{X}_{\mathrm{q}}$ & $\sqrt{3}-\mathrm{T}_{1}+\mathrm{T}_{2}$ \\
\hline 2 & $\mathrm{X}_{\mathrm{d}}+\left(\mathrm{X}_{\mathrm{q}}>>1\right)$ & $\left(\mathrm{X}_{\mathrm{q}}>>1\right)-\mathrm{X}_{\mathrm{d}}$ & $\sqrt{3}-\mathrm{T}_{1}+\mathrm{T}_{2}$ \\
\hline 3 & $\mathrm{X}_{\mathrm{q}}$ & $\mathrm{X}_{\mathrm{d}}-\left(\mathrm{X}_{\mathrm{q}}>>1\right)$ & $\sqrt{3}-\mathrm{T}_{1}+\mathrm{T}_{2}$ \\
\hline 4 & $-\mathrm{X}_{\mathrm{d}}+\left(\mathrm{X}_{\mathrm{q}}>>1\right)$ & $-\mathrm{X}_{\mathrm{q}}$ & $\sqrt{3}-\mathrm{T}_{1}+\mathrm{T}_{2}$ \\
\hline 5 & $-\mathrm{X}_{\mathrm{d}}-\left(\mathrm{X}_{\mathrm{q}}>>1\right)$ & $\mathrm{X}_{\mathrm{d}}-\left(\mathrm{X}_{\mathrm{q}}>>1\right)$ & $\sqrt{3}-\mathrm{T}_{1}+\mathrm{T}_{2}$ \\
\hline 6 & $-\mathrm{X}_{\mathrm{q}}$ & $\mathrm{X}_{\mathrm{d}}+\left(\mathrm{X}_{\mathrm{q}}>>1\right)$ & $\sqrt{3}-\mathrm{T}_{1}+\mathrm{T}_{2}$ \\
\hline
\end{tabular}

TABLE III. PWM GENERATION FOR SECTOR-1

\begin{tabular}{|l|l|l|l|}
\hline Sector $=\mathbf{1}$ & $P W M-a$ & $P W M-b$ & $P W M-c$ \\
\hline Counter & 1 & 0 & 0 \\
\hline $\mathrm{T}_{01}$ & 1 & 1 & 0 \\
\hline $\mathrm{T}_{01}+\mathrm{T}_{1}$ & 1 & 1 & 1 \\
\hline $\mathrm{T}_{01}+\mathrm{T}_{1}+\mathrm{T}_{2}$ & 1 & 1 & 1 \\
\hline $\mathrm{T}_{0}+\mathrm{T}_{1}+\mathrm{T}_{2}$ & 1 & 1 & 0 \\
\hline $\mathrm{T}_{0}+\mathrm{T}_{1}+\mathrm{T}_{2}+\mathrm{T}_{01}$ & 1 & 0 & 0 \\
\hline $\mathrm{T}_{0}+\mathrm{T}_{1}+2 \mathrm{~T}_{2}+\mathrm{T}_{01}$ & 0 & 0 & 0 \\
\hline $\mathrm{T}_{0}+2 \mathrm{~T}_{1}+2 \mathrm{~T}_{2}+\mathrm{T}_{01}$ & 0 & & \\
\hline
\end{tabular}

\section{Results AND Discussion}

The proposed Digital Space Vector PWM (DSV-PWM) module is designed and implemented on Artix-7 FPGA for $3 \Phi-V S I$ applications. The DSV-PWM is designed using Xilinx ISE 14.7 Environment with Verilog HDL and simulated on Modelsim 6.5f Simulator. The DSV-PWM is implemented on Artix-7 FPGA with the device of XC7A100T-3 CSG 324. The DSV-PWM Module provides low-cost FPGA implementation with high performance. The simulation results of the DSV-PWM Module are represented in Fig. 8.

Once clock (clk) is activated with active-low reset (rst) signal, The DSV-PWM operation starts. The 3-bit select line (sel) is used in the Sector generation module to perform the signed shifting operation. The 3-phase va, vb, and vc are 8-bit voltage inputs and generate the DSV-PWM outputs like $\mathrm{xd}$ and xq by Xqd Module 8-bit outputs, 3-bit selection generation output, $\mathrm{t} 0, \mathrm{t} 1$, and $\mathrm{t} 2$ are 8-bit switching time outputs and final pa, pb, pc are PWM outputs.

The PWM outputs are generated based on 3-Phase voltage inputs along with sector generation and switching time module. The Resource utilization of DSV-PWM is generated after synthesis operation in Xilinx Tool. The DSV-PWM resource utilization in terms of Chip area, Timing analysis, and power Utilization are tabulated in Table IV.

The DSV-PWM utilized slice register of 27, slice LUT's of 337, and LUT-FF pairs of 27 on Artix-7 FPGA. The DSVPWM module works at $597.83 \mathrm{MHz}$ with a minimum period of $1.67 \mathrm{~ns}$ and a combinational delay of $2.17 \mathrm{~ns}$. The power utilization is analyzed for the DSV-PWM module using the Xilinx Xpower analyzer, and it consumes the total power of $110 \mathrm{~mW}$, which includes the static power of $82 \mathrm{~mW}$ and dynamic power of $28 \mathrm{~mW}$. The overall power utilization of DSA-PWM is $100 \mathrm{~mW}$, which is quite less and suitable for real-time power electronics applications.

The DSV-PWM module contains four main sub-modules, namely, Xdq Module, Sector generation module (SGM), Square root Module (SRM), and CSA module. The slice LUT's and the Combination delay of DSV-PWM sub-modules are tabulated in Table V. The $\mathrm{X}_{\mathrm{dq}}$, SGM, SRM, CSA utilize 24, 42, 8, and 12 slice LUTs respectively. Similarly, the Xdq, SRM and CSA have a combinational delay of $2.1 \mathrm{~ns}, 1.74 \mathrm{~ns}$, and 2.52ns, respectively. The remaining Slice -LUT's of DSV-PWM Module are utilized by the Switching time module and PWM generation Module. 
The proposed DSV-PWM is compared with similar existing SV-PWM technique with better improvements in design and hardware constraints. The DSV-PWM module is compared with existing SV-PWM [23] and is tabulated in Table VI for resource constraints.

The DSV-PWM improves around $69 \%, 14 \%$, and $57 \%$ of less overhead in Slice registers, Slice LUTs, and Maximum frequency $(\mathrm{MHz})$, respectively than the existing SV-PWM [23] technique. Similarly, the DSV-PWM dynamic power utilization by using different clock frequency is compared with existing SV-PWM [23] with better improvements is tabulated in Table VII, and graphical representation is showed in Fig. 9.

The DSV-PWM consumes the dynamic power of 7, 14, 21, and $28 \mathrm{~mW}$, which is quite less compared to the existing SVPWM [23] technique with 23, 28, 33, and $37 \mathrm{~mW}$ against clock frequency of 25, 50, 75 and $100 \mathrm{MHz}$ respectively.

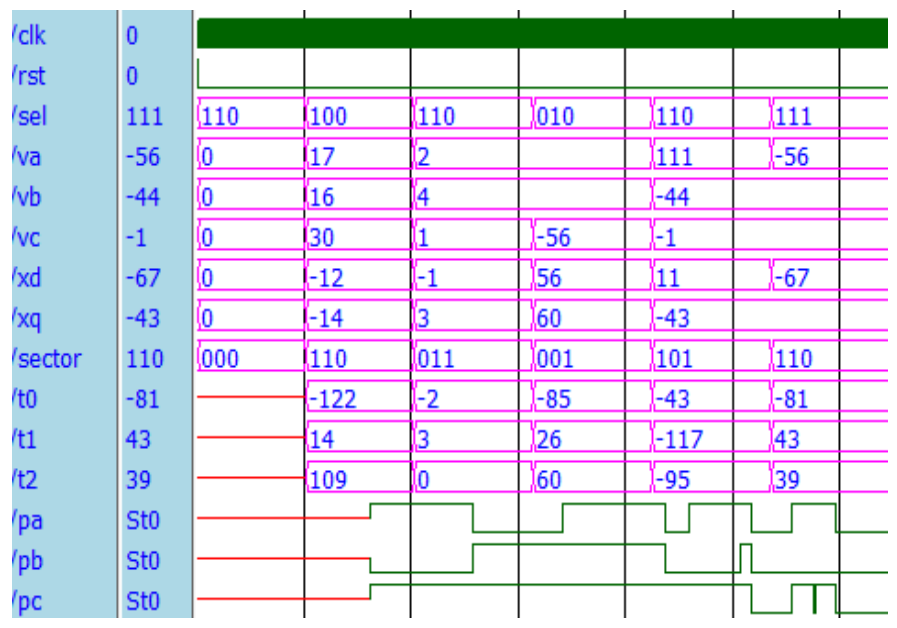

Fig. 8. Simulation Results of DSV-PWM Module.

TABLE IV. HARDWARE RESOURCE UtILIZATION OF DSV-PWM MOdULE ON ARTIX-7 FPGA

\begin{tabular}{|l|l|}
\hline Resources & DSV-PWM \\
\hline Chip Area & 27 \\
\hline Slice Registers & 337 \\
\hline Slice LUTs & 27 \\
\hline LUT-FF pairs & 1.673 \\
\hline Time & 597.836 \\
\hline Minimum period (ns) & 2.17 \\
\hline Max. Frequency (MHz) & \multicolumn{2}{|l}{} \\
\hline Combinational Delay (ns) & 0.028 \\
\hline Power & 0.11 \\
\hline Dynamic Power (W) & \\
\hline Total Power (W) &
\end{tabular}

TABLE V. SLICES LUT’S AND COMBINATIONAL DELAY (NS) OF DSVPWM- SUB MODULES

\begin{tabular}{|l|l|l|}
\hline Sub Modules & $\begin{array}{l}\text { Slice } \\
\text { LUTs }\end{array}$ & $\begin{array}{l}\text { Combinational } \\
\text { Delay (ns) }\end{array}$ \\
\hline
\end{tabular}

\begin{tabular}{|l|l|l|}
$\mathrm{X}_{\mathrm{dq}}$ Module & 24 & 2.106 \\
\hline Sector Generation Module & 42 & NA \\
\hline Square Root Module & 8 & 1.747 \\
\hline CSA Module & 12 & 2.523 \\
\hline
\end{tabular}

TABLE VI. RESOURCE COMPARISON OF DSV-PWM MODULE WITH [23]

\begin{tabular}{|l|l|l|}
\hline Resources & Ref [23] & Proposed \\
\hline FPGA Device & Cyclone II & Artix-7 \\
\hline Slice Registers & 88 & 27 \\
\hline Slice LUT's & 392 & 337 \\
\hline Max. Frequency (MHz) & 253.85 & 597.836 \\
\hline
\end{tabular}

TABLE VII. DYNAMIC POWER (MW) COMPARISON OF DSV-PWM MODULE WITH [23]

\begin{tabular}{|l|l|l|}
\hline \multirow{2}{*}{ Clock Frequency (MHz) } & \multicolumn{2}{|l|}{ Dynamic Power $(\mathbf{m W})$} \\
\cline { 2 - 3 } & Ref [23] & Proposed \\
\hline 25 & 23 & 7 \\
\hline 50 & 28 & 14 \\
\hline 75 & 33 & 21 \\
\hline 100 & 37 & 28 \\
\hline
\end{tabular}

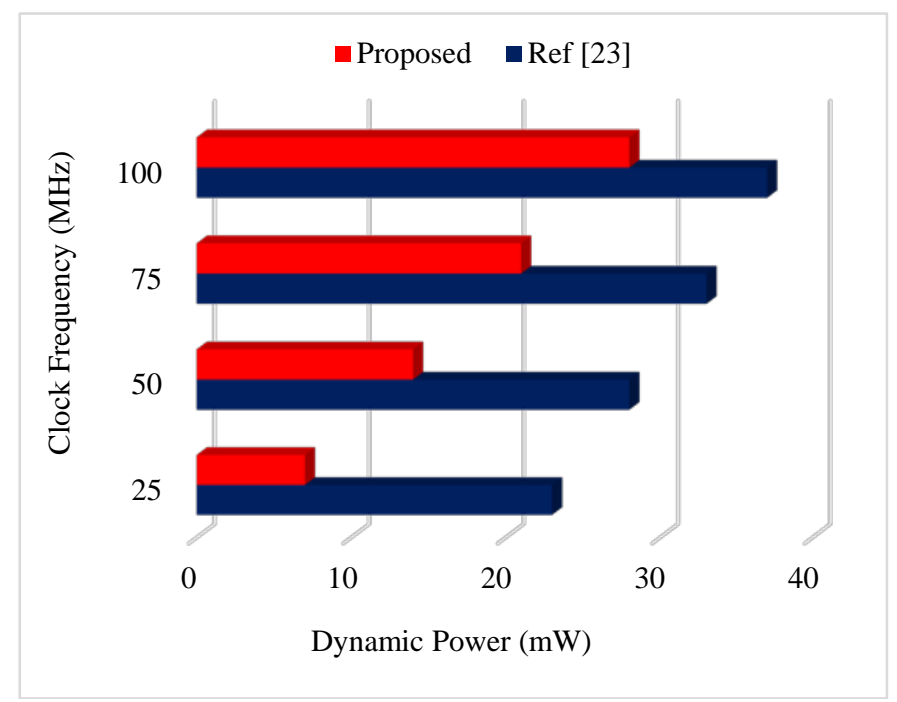

Fig. 9. Graphical Representation of DSV-PWM Dynamic Power (mW) by Concerning [23].

\section{CONCLUSION AND FUTURE WORK}

The DSV-PWM module is designed and implemented in Artix-7 FPGA. The DSV-PWM Module contains Xdq Module, Sector generation module (SGM), Switching time module, and PWM Generation Module. These modules are designed using simple logical operators and combinational circuits, which improve the hardware constraints like chip area, Power and frequency along with the performance. The DSV-PWM uses less chip area $(<1 \%), 110 \mathrm{~mW}$ total power and works at $597.836 \mathrm{MHz}$ operating frequency on the FPGA device. The DSV-PWM method is also compared with the existing SV-PWM method with more considerable improvement in chip area, Frequency, and Dynamic power. In 
the future, The DSV-PWM will be used in real-time power electronics applications and also to optimize the hardware constraints.

\section{REFERENCES}

[1] Yu, Zhenyu, Arefeen Mohammed, and Issa Panahi. "A review of three PWM techniques." In Proceedings of the 1997 American Control Conference (Cat. No. 97CH36041), vol. 1, pp. 257-261. IEEE, 1997.

[2] Tzou, Ying-Yu, and Hau-Jean Hsu. "FPGA realization of space-vector PWM control IC for three-phase PWM inverters." IEEE Transactions on power electronics 12, no. 6 (1997): 953-963.

[3] Patil, Sumit R., and V. N. Kalkhambkar. "Hybrid space vector pulse width modulation voltage source inverter-a review." In 2017 International Conference on Data Management, Analytics, and Innovation (ICDMAI), pp. 200-204. IEEE, 2017.

[4] Pongiannan, R. K., and N. Yadaiah. "FPGA based space vector PWM control IC for three-phase induction motor drive." In 2006 IEEE International Conference on Industrial Technology, pp. 2061-2066. IEEE, 2006.

[5] Rajendran, R., and N. Devarajan. "FPGA implementation of space vector PWM technique for voltage source inverter fed induction motor drive." In 2009 Second International Conference on Computer and Electrical Engineering, vol. 2, pp. 422-426. IEEE, 2009.

[6] Alvarez, Jacobo, Oscar Lopez, Francisco D. Freijedo, and Jesús DovalGandoy. "Digital parameterizable VHDL module for multilevel multiphase space vector PWM." IEEE Transactions on Industrial Electronics 58, no. 9 (2010): 3946-3957.

[7] Wang, Yingnan, and Uwe Schaefer. "Real-time simulation of an FPGA based space vector PWM controller." In SPEEDAM 2010, pp. 833-838. IEEE, 2010.

[8] Somlal, Jarupula, M. Venu Gopala Rao, and S. Prabhakar Karthikeyan. "Experimental investigation of an indirect current-controlled FuzzySVPWM based Shunt Hybrid Active Power Filter." In 2016 IEEE Region 10 Conference (TENCON), pp. 801-806. IEEE, 2016.

[9] Rait, Aishanou Osha, and Praveen Bhosale. "FPGA implementation of space vector PWM for speed control of 3-phase induction motor." In 2011 International Conference on Recent Advancements in Electrical, Electronics and Control Engineering, pp. 221-225. IEEE, 2011.

[10] Janik, Dusan, Tomas Kosan, Jaroslav Sadsky, and Zdenek Peroutka. "Implementation of SVPWM algorithm without trigonometric functions." In 2014 International Conference on Applied Electronics, pp. 131-134. IEEE, 2014.

[11] Holtz, Joachim, Markus Höltgen, and Jens Onno Krah. "A space vector modulator for the high-switching frequency control of three-level SiC inverters." IEEE Transactions on Power Electronics 29, no. 5 (2013): 2618-2626.

[12] Kassas, Mahmoud, and Naseer Ahmed. "Simulation and Implementation of Space Vector PWM Using Look-Up Table." Arabian Journal for Science and Engineering 39, no. 6 (2014): 4815-4828.

[13] ÇELIK, Hakan, Mahmut Temel ÖZDEMIR, and Eyyüp ÖKSÜZTEPE. "Generation of Space Vector PWM Signals Based on the FPGA in Real Time." International Journal of Natural and Engineering Sciences 9, no. 3 (2015): 54-59.

[14] Liang, Xuexiu, Min Luo, Bo Zhao, Yanwei Yuan, and Zhi Chen. "Research and implementation of SVPWM control algorithm based on FPGA." In 2016 IEEE International Conference on Mechatronics and Automation, pp. 22-26. IEEE, 2016.

[15] Lotfi, Elhabib, Mustapha Elharoussi, and Elhassane Abdelmounim. "VHDL Design and FPGA Implementation of the PWM Space Vector of an AC Machine Powered by a Voltage Inverter." In Proceedings of the Mediterranean Conference on Information \& Communication Technologies 2015, pp. 41-47. Springer, Cham, 2016.

[16] Salem, Aboubakr, Frederik De Belie, and Jan Melkebeek. "A novel space-vector PWM computations for a dual three-level T-type converter applied to an open end-winding induction machine." In 2016 Eighteenth International Middle East Power Systems Conference (MEPCON), pp. 633-638. IEEE, 2016.

[17] Pu, Tianyu, Feifei Bu, Wenxin Huang, and Lin Zhu. "Implementation of random SVPWM strategy for three-phase voltage source inverter based on FPGA." In 2017 20th International Conference on Electrical Machines and Systems (ICEMS), pp. 1-4. IEEE, 2017.

[18] Khiavi, A. Moallemi, J. Sobhi, Z. Daie Koozehkanani, and M. Farhadi Kangarlu. "FPGA-based reconfigurable PWM generator for power electronic converter applications." Journal of Control, Automation, and Electrical Systems 28, no. 4 (2017): 516-531.

[19] García, Raymundo Cordero, Igor Esdras Silva Ono, Vitória dos Santos Fahed, and João Onofre Pereira Pinto. "Simplified educational platform for SVPWM control of a two-level three-phase inverter using Matlab GUI and FPGA." In 2017 Brazilian Power Electronics Conference (COBEP), pp. 1-6. IEEE, 2017.

[20] Sumam, M. J., and G. Shiny. "Rapid prototyping of high-performance FPGA controller for an induction motor drive." In 2018 8th International Conference on Power and Energy Systems (ICPES), pp. 76-80. IEEE, 2018.

[21] Sumam, M. J., and G. Shiny. "Prototype Non-Volatile FPGA SVPWM Controller for 3-Level Inverter." In 2018 8th IEEE India International Conference on Power Electronics (IICPE), pp. 1-6. IEEE, 2018.

[22] Chinmaya, K. A., and Girish Kumar Singh. "Experimental analysis of various space vector pulse width modulation (SVPWM) techniques for dual three-phase induction motor drive." International Transactions on Electrical Energy Systems 29, no. 1 (2019): e2678.

[23] Rashidi, Bahram, and Mehran Sabahi. "High-performance FPGA based digital space vector PWM three-phase voltage source inverter." International Journal of Modern Education and Computer Science 5, no. 1 (2013): 62. 